DOI: https://doi.org/10.47405/mjssh.v6i8.914

\begin{tabular}{|c|c|}
\hline 4 & Malaysian Journal of Social Sciences and Humanities (MJSSH) \\
\hline $\begin{array}{l}\text { Malaysian Juoural of } \\
\text { Social ccciecces and }\end{array}$ & Volume 6, Issue 8, August 2021 \\
\hline (MJ-sSH) & e-ISSN : 2504-8562 \\
\hline & $\begin{array}{l}\text { Journal home page: } \\
\text { www.msocialsciences.com }\end{array}$ \\
\hline
\end{tabular}

\title{
Keibubapaan Digital dan Mediasi Ibu Bapa Terhadap Penggunaan Internet Remaja di Malaysia
}

\author{
Haslina Mohamed Hassan', Mohd Azul Mohamad Salleh², Abdul Latiff Ahmad ${ }^{2}$ \\ ${ }^{1}$ Fakulti Komunikasi dan Pengajian Media, Universiti Teknologi MARA Shah Alam \\ 2Pusat Kajian Media dan Komunikasi, Fakulti Sains Sosial dan Kemanusiaan, Universiti Kebangsaan Malaysia (UKM) \\ Correspondence: Haslina Mohamed Hassan (linahash1992@gmail.com)
}

\begin{abstract}
Abstrak
Internet dan penggunaan peranti digital adalah satu keperluan dalam kehidupan seharian di persekitaran digital. Kini penggunaan teknologi digunakan untuk pelbagai tujuan seperti hiburan, pengetahuan dan tujuan interaksi. Bagaimanapun, internet pada asasnya diperkenalkan dengan anggapan bahawa pengguna adalah golongan dewasa. Namun pada era ini, kanak-kanak dan remaja tidak ketinggalan dengan arus teknologi ini. Akibatnya mereka berkemungkinan terdedah kepada risiko seperti isi kandungan yang tidak sesuai dengan usia dan masalah ketagihan internet. Oleh itu, ibu bapa pada era digital perlu ambil perhatian dalam usaha untuk memantau penggunaan internet anak-anak mereka. Sehubungan itu, artikel ini membincangkan secara konsep tentang strategi ibu bapa dalam memantau penggunaan internet remaja. Tujuannya adalah kerana remaja sedang mengalami proses peralihan daripada kanak-kanak menuju kematangan dan sentiasa inginkan autonomi dan mencari identiti mereka. Internet menjadi platform untuk memenuhi keperluan masa lapang dan emosi mereka. Sehubungan itu, artikel ini turut mengupas tentang keibubapaan pada era digital, penggunaan internet oleh remaja serta kesan internet terhadap remaja. Berdasarkan kupasan itu, artikel ini mengetengahkan mediasi ibu bapa sebagai strategi pemantauan terhadap penggunaan internet remaja. Terdapat tiga dimensi mediasi yang dibincangkan iaitu mediasi aktif, mediasi sekatan dan mediasi penggunaan bersama. Dalam konteks artikel ini, mediasi ibu bapa merujuk kepada pendekatan komunikasi interpersonal di antara ibu bapa dan anak-anak berhubung dengan perihal penggunaan internet. Pelaksanaan pemantauan ibu bapa ini menjadi asas untuk remaja mengakses internet bagi tujuan kebaikan. Seterusnya memupuk keprihatinan ibu bapa terhadap keselamatan dalam talian disamping menyokong penggunaan internet secara positif dan meminimumkan kesan negatif dalam kalangan remaja.
\end{abstract}

Kata kunci: keibubapaan, digital, remaja, internet, mediasi ibu bapa

\section{Digital Parenting and Parental Mediation on Teenagers' Internet Use in Malaysia}

\begin{abstract}
The internet and the adoption of digital devices are quintessential in everyday life in a digital atmosphere. People employ technology for diverse goals such as entertainment, knowledge and interaction. The internet was invented for adults users. Nevertheless, in this epoch, children and teenagers are involved in this technology employment. Thus, they have been exposed to inappropriate content and prone to internet addiction predicaments. Therefore, parents nowadays need to pay
\end{abstract}


attention to mediate their children's internet usage. This article conceptually discussed parental strategies in mediating teenagers' internet use. Teenagers include the transition from childhood to maturity and constantly demand autonomy and a search for their identity. Hence, the internet works as a platform for them to spend their time and cater their emotional needs. This article also discussed parenting in the digital age, the use of the internet by teenagers, and the internet's impact on them. Based on that analysis, this article highlighted parental mediation as a mediating strategy for teenagers' internet use. There were three dimensions of mediations addressed, particularly active mediation, restriction mediation and co-use mediation. In this article, parental mediation referred to an interpersonal communication approach between parents and children concerning internet use. The implementation of parental mediation became the basis for teenagers to access the internet for their benefit. It further nurtures a parental interest in online safety while supporting beneficial internet use and minimising adverse impacts among teenagers.

Keywords: parenting, digital, teenagers, internet, parental mediation

\section{Pengenalan}

Teknologi khususnya internet dan media baharu adalah satu keperluan dalam kehidupan manusia masa kini. Ledakan teknologi yang berlaku di serata dunia ini turut membawa kepada peningkatan dalam penggunaan peranti pintar dalam kalangan masyarakat. Perkembangan ini secara tidak langsung membawa kepada kehidupan seharian dalam persekitaran digital. Dalam konteks penggunaan internet pada era digital, golongan remaja juga tidak ketinggalan dengan arus teknologi seperti menggunakan internet dan peranti digital seperti telefon pintar, komputer dan komputer tablet. Pola dan kadar penggunaan media sosial dan internet dalam kalangan remaja juga kian meningkat sejak kebelakangan ini. Peningkatan penggunaan telefon pintar dalam kalangan remaja adalah antara faktor penyebab kepada meningkatnya penggunaan media sosial dan internet oleh golongan ini (Chassiakos et al., (2016). Laporan Berita Harian pada 22 Oktober 2017 mendedahkan hasil kajian oleh CyberSecurity Malaysia dan Kementerian Pendidikan Malaysia pada 2016 mendapati hampir 92.5 peratus pengguna internet tegar adalah remaja berusia 13 hingga 17 tahun.

Oleh kerana remaja adalah antara pengguna internet yang aktif, ibu bapa perlu membabitkan diri secara langsung kerana remaja perlu diawasi, diperhatikan dan diberi tunjuk ajar tentang keselamatan ketika melayari internet. Isu ini selaras dengan deklarasi oleh United Nations iaitu The Declaration of Children's Rights yang memetik bahawa adalah menjadi tanggungjawab ibu bapa untuk memberi arahan, membimbing, memberi garis panduan dan mengawasi anak-anak dan remaja mereka tentang penggunaan web (Internet) di rumah, di sekolah. di rumah rakan mereka, di kafe internet dan sebagainya sehingga mereka layak untuk berdikari pada usia 18 tahun (Unicef, 2017).

Walaupun akses untuk rangkaian internet semakin meningkat dengan adanya pelbagai kemudahan wifi, namun ibu bapa berhadapan dengan cabaran dalam usaha untuk mengawal isi kandungan yang diakses oleh anak-anak mereka ketika berada dalam talian. Utusan Malaysia bertarikh 25 September 2016 melaporkan antara sebab ibu bapa cuai mengawasi adalah kerana menyangka anak-anak sedang sibuk membuat carian dari internet berkaitan kerja sekolah. Walhal anak-anak mereka mungkin sedang leka dengan permainan dalam talian. Faktor ini adalah kerana peralatan teknologi seperti telefon pintar, komputer tablet, komputer riba dan komputer adalah peralatan yang digunakan secara peribadi.

Sifat peralatan ini membolehkan remaja melayari dunia digital tanpa batasan tempat, masa dan tujuan. remaja bebas menggunakan teknologi ini bersendirian khususnya di bilik tidur masing-masing. Akibatnya, remaja berpotensi untuk terdedah kepada pelbagai risiko seperti tidak memahami isu privasi dalam talian serta isi kandungan yang tidak sesuai dengan umur dan tahap pemikiran. Selain itu risiko lain seperti buli siber, pelacuran siber, ketagihan internet, pornografi juga berupaya menyebabkan gangguan emosi, tekanan perasaan serta menjejaskan pergaulan sosial kepada pengguna muda (Elhai et al., 2017). Keadaan ini secara tidak langsung memberi kesan negatif kepada remaja berkenaan seterusnya kepada keluarga, masyarakat dan negara. 
Sementara itu beberapa usaha telah diperkenalkan dalam menghadapi isu keselamatan dalam talian. Banyak maklumat dan panduan disediakan oleh pelbagai organisasi berkaitan sama ada di Malaysia atau luar negara yang antaranya adalah Suruhanjaya Komunikasi dan Multimedia Malaysia (SKMM), CyberSecurity Malaysia, Unicef serta National Crime Prevention Council (NCPC) tentang risiko teknologi terhadap kanak-kanak dan remaja. Selain garis panduan oleh organisasi terbabit, syarikat telekomunikasi Celcom turut memperkenalkan aplikasi KidSafe yang memudahkan ibu bapa untuk mengawal dan mengesan aktiviti internet anak-anak menerusi rangkaian talian (The Star, 2017). Digi Telecommunications Malaysia juga memperkenalkan program Safe Internet yang bertujuan untuk memperkasakan rakyat Malaysia yang mempunyai kemahiran digital untuk menjadi warga dalam talian yang lebih berdaya tahan dan bertanggungjawab (Digi.com.my, 2021). Kapersky Safe Kids turut diperkenalkan untuk ibu bapa memantau feed media sosial, perbualan dan mesej anak-anak. Kaedahkaedah ini bukan bertujuan untuk mengintip tetapi sebagai pemantauan di sebalik memberi ruang kepada anak-anak menggunakan teknologi (Utusan, 2018). Garis panduan dan aplikasi pemantauan adalah usaha yang membantu institusi keluarga. Namun, usaha yang utama harus direalisasikan oleh ibu bapa dan pada masa kini mereka perlu memiliki ciri dan strategi bagi memantau kegiatan anakanak dalam talian.

Ibu bapa yang celik teknologi akan turut serta secara aktif dengan aktiviti dalam talian bersama anakanak mereka (Wisniewski et al., 2014). Faktor ini adalah berdasarkan kesedaran ibu bapa yang berpandangan bahawa penggunaan teknologi oleh remaja hendaklah dalam keadaan terkawal. Artikel ini adalah penting kerana isu tentang hubungan ibu bapa dan remaja dalam konteks komunikasi keluarga mengalami perubahan akibat penggunaan teknologi. Penggunaan internet berlebihan juga berisiko menjejaskan hubungan kekeluargaan disebabkan kurangnya komunikasi bersemuka di antara ibu bapa dan anak-anak. Bagaimanapun, dalam masa yang sama penggunaan internet juga memberi manfaat kepada remaja sama ada untuk menambah pengetahuan, berhubung dan berhibur. Oleh itu, peranan ibu bapa adalah penting dalam mengawasi aktiviti yang anak-anak mereka tonton, dengar dan baca daripada internet. Pelbagai kebimbangan timbul tentang keselamatan dalam talian yang turut mempengaruhi keselamatan remaja secara mental dan fizikal. Oleh yang demikian isu yang diketengahkan dalam artikel ini adalah penting kerana ibu bapa perlu sedar tentang perkembangan teknologi yang serba banyak telah mengubah corak keibubapaan pada era digital ini.

\section{Keibubapaan Digital di Malaysia}

Perkembangan internet di Malaysia bermula pada tahun 1987 oleh Malaysian Institute of Microelectronic Systems (MIMOS) menerusi projek Rangkaian Komputer Malaysia (RangKom) (Ali \& Mohd Safar, 2011). Seterusnya pelancaran Joint Advanced Integrated Networking (JARING) sebagai penyedia perkhidmatan internet yang utama di negara ini pada tahun 1990. Tahun 1995 dilihat sebagai permulaan kepada pengenalan internet di negara ini dan pada tahun 1996, enjin carian dan syarikat portal web pertama di Malaysia iaitu Cari Internet diperkenalkan (Ali et al., 2013; Pillai, 2001). Bagaimanapun, pada tahun 1990an itu, penggunaan internet masih terhad dan akses lazimnya di sektor kerajaan dan swasta serta di institusi pengajian tinggi dan kafe siber. Ketika itu juga penggunaan internet adalah untuk mel elektronik dan melayari laman sesawang untuk tujuan pencarian maklumat menerusi Web 1.0.

Apabila internet diperluaskan kepada Web 2.0 pada awal tahun 2000 yang salah satunya bercirikan interaktiviti maka media sosial mula bertapak di alam maya. Antara media sosial awal di Malaysia adalah MySpace, Friendster diikuti oleh Facebook, Twitter, Instagram, Snapchat serta aplikasi mesej WhatsApp dan Telegram yang membolehkan pengguna untuk berkumpul secara maya untuk berhibur, berinteraksi serta berkongsi maklumat. Penggunaan media sosial dan internet juga adalah meluas tanpa mengira umur termasuk kanak-kanak dan remaja.

Berikutan perkembangan penggunaan internet dalam kalangan remaja dan kanak-kanak, maka ibu bapa turut terpanggil untuk seiring sejalan dengan anak-anak dalam menggunakan media baharu ini. Faktor ini adalah kerana internet pada asasnya dibangunkan dengan anggapan bahawa pengguna adalah 
golongan dewasa (Unicef, 2017). Oleh itu, kebanyakan isi kandungan dan aplikasi di internet lebih memihak kepada keperluan orang dewasa. Bagaimanapun, apabila akses kepada kemudahan internet diperluaskan dan semakin banyak komputer dan telefon pintar mampu dimiliki maka penggunaan internet dan peranti digital bersifat pintar juga mula meresapi kepada golongan kanak-kanak dan remaja. Berdasarkan kepada laporan oleh Suruhanjaya Komunikasi dan Multimedia Malaysia, kira-kira 50.4 peratus kanak-kanak memiliki telefon pintar pada usia 12 tahun (Sinar Harian, 2019). Tambahan pula selaras dengan usaha kerajaan untuk meningkatkan literasi digital setiap rakyat Malaysia menerusi inisiatif MyDigital yang dilancarkan pada tahun 2021 serta pandemik Covid 19 yang melanda seluruh dunia sejak tahun 2020 menyebabkan kanak-kanak dan remaja tidak terkecuali dalam mengikuti arus keperluan terhadap internet pada masa kini.

Menyedari keadaan ini, penggunaan internet dan peranti digital seperti komputer dan telefon pintar adalah satu keperluan dan bukan lagi barangan mewah. Sehubungan itu, corak interaksi antara ibu bapa, anak-anak dengan orang sekeliling masa kini dipengaruhi oleh komunikasi elektronik seperti WhatsApp dan media sosial. Berikutan kanak-kanak dan remaja pada hari ini membesar dalam persekitaran digital, ibu bapa perlu peka dengan kesan sama ada positif atau negatif penggunaan teknologi media terhadap kanak-kanak (Noorma et al., 2018) dan remaja. Kanak-kanak dan remaja menggunakan internet untuk pelbagai tujuan seperti mencari maklumat, media sosial, permainan dalam talian, berkomunikasi menerusi mesej, mendengar muzik, menonton drama atau TV internet serta banyak lagi. Sehubungan itu, sesetengah daripada aktiviti ini menyebabkan ketagihan kepada internet. Suruhanjaya Komunikasi dan Multimedia Malaysia turut melaporkan bahawa 78.8 peratus pengguna internet khususnya kanak-kanak di negara ini ketagih internet (Sinar Harian, 2019).

Ibu bapa digital memiliki ciri celik teknologi serta menyokong anak-anak menggunakan media dan teknologi. Bagaimanapun, sokongan dan galakkan ini disertakan dengan peraturan bagi mengelakkan kesan buruk terhadap anak-anak akibat penggunaan media dan teknologi (Nurhamizah \& Asbah, 2019). Dalam masa yang sama ibu bapa pada era digital mengajar anak-anak tentang tanggungjawab apabila menggunakan teknologi maklumat dan komunikasi seperti internet dan peranti yang merangkumi telefon pintar, komputer dan komputer tablet. Ini bermakna ibu bapa perlu mempunyai strategi dan peraturan dalam memantau penggunaan internet anak-anak bagi memastikan mereka selamat ketika dalam talian. Keibubapaan digital adalah cabaran baru bagi ibu bapa di Malaysia memandangkan ibu bapa kepada kanak-kanak dan remaja pada masa kini tidak dibesarkan dalam persekitaran digital berbanding anak-anak mereka. Oleh itu proses keibubapaan digital ini memerlukan masa untuk ibu bapa menyesuaikan diri dengan kemajuan teknologi yang pantas ini serta bergantung kepada kemahiran digital masing-masing.

Setakat ini, kajian ke atas ibu bapa yang mempunyai anak remaja mendapati pengetahuan tentang kaedah mencegah dan menangani penyalahgunaan internet masih rendah. Keadaan ini adalah kritikal kerana semakin ramai 'netizen' di Malaysia adalah kanak-kanak dan remaja. Dalam masa yang sama ibu bapa adalah sumber utama untuk mendidik anak-anak tentang penggunaan internet secara berhemah dan bertanggungjawab. Selain itu, kesan penggunaan teknologi dan internet lazimnya dikaitkan dengan tanggapan negatif. Bagaimanapun, tertakluk kepada strategi pemantauan ibu bapa yang dipraktikkan serta jenis medium yang digunakan.

Dalam usaha untuk mengecapi keibubapaan digital, ibu bapa boleh turut menggunakan teknologi seperti internet dan peranti digital untuk meningkatkan pengetahuan tentang dunia digital. Meskipun tidak membesar dalam suasana digital namun kebanyakan ibu bapa kepada kanak-kanak dan remaja pada hari ini telah mendapat serba sedikit pendedahan kepada penggunaan internet dan komputer seperti mengakses laman sesawang, forum, perbincangan dalam talian dan blog (Lupton et al., 2016) serta bersembang dalam talian (online chatting) dan mel elektronik ketika di zaman universiti dan alam pekerjaan. Seterusnya kemunculan peranti mudah alih seperti telefon pintar, komputer tablet, Wi-fi, media sosial dan pelbagai aplikasi di internet membolehkan ibu bapa untuk meningkatkan pengetahuan dan kemahiran digital mereka sebagai usaha merealisasikan praktis keibubapaan digital (Lupton et al., 2016). Sehubungan itu dalam konteks keibubapaan digital, ibu bapa dan anak-anak perlu seiring menyelami alam maya supaya tidak ketinggalan dengan arus teknologi yang pantas berubah di samping 
memanfaatkan teknologi digital untuk kebaikan dan dalam masa yang sama menghindari salah guna kemudahan teknologi ini.

\section{Penggunaan Internet Remaja}

Remaja adalah peringkat peralihan dari alam kanak-kanak menuju ke alam dewasa. Pada peringkat ini remaja juga mula bertindak balas kepada tuntutan emosi dan autonomi untuk mencari identiti dan penampilan diri sendiri. Salah satu cara untuk mereka meluahkan tuntutan ini adalah menerusi penggunaan internet. Golongan remaja menggunakan internet untuk pelbagai aktiviti yang lazimnya untuk tiga tujuan utama iaitu jalinan persahabatan, mendapatkan maklumat dan hiburan. Tujuan ini termasuklah menggunakan media sosial, bersembang, enjin pencarian, permainan dalam talian, menonton filem serta drama dan mendengar muzik. Kegiatan remaja di internet seharusnya digalakkan untuk mereka menjadi celik teknologi pada era digital.

Media elektronik dan internet telah menjadi bahagian asas dalam kehidupan kanak-kanak dan remaja (Chen \& Shi, 2019). Secara amnya, kanak-kanak dan remaja menggunakan internet sebagai medium untuk pendidikan, perkongsian maklumat, komunikasi dan perkembangan peribadi (Lakshmana, 2017). Pemilikan telefon pintar, komputer riba dan komputer tablet adalah antara faktor untuk mereka menggunakan internet. Kini, hampir setiap kanak-kanak dan remaja menggunakan peranti digital yang disambungkan ke internet untuk pelbagai tujuan ini. Bagi remaja, telefon pintar, komputer riba dan komputer meja atau komputer peribadi adalah peranti untuk akses kepada internet. Sementara untuk kanak-kanak yang lebih muda biasanya menggunakan komputer tablet atau berkongsi peranti seperti komputer peribadi atau komputer riba (Iqbal, 2021) dengan adik-beradik.

Dari segi penggunaan media sosial, terdahulu Facebook menjadi platform untuk remaja mengekspresikan diri dan membentuk identiti mereka (Normah et al., 2013). Dalam konteks ruang siber, identiti penting bagi anak muda kerana di platform inilah mereka mempunyai kebebasan untuk membina identiti dan juga membina hubungan dengan rakan sebaya mereka. Walau bagaimanapun, Facebook tidak lagi menjadi pilihan dominan dalam kalangan remaja masa kini. Remaja sekarang lebih menggemari Youtube, Instagram dan Snapchat (Anderson \& Jiang, 2018). Menerusi internet dan media sosial, remaja dapat berinteraksi dan berkongsi gambar dengan rakan-rakan serta mengikuti maklumat terkini tentang rakan mereka. Selain menggunakan media sosial untuk persahabatan, ia juga digunakan untuk mendapatkan populariti dalam kalangan rakan-rakan sebaya.

Tidak dinafikan bahawa penggunaan jaringan sosial adalah kunci utama di dalam proses membina persahabatan dan meraih populariti. Bagi remaja yang berasa tersisih secara fizikal mendapati alam maya adalah platform untuk mencari kawan baru dalam talian. Meskipun pengguna remaja ini mempunyai sebab tersendiri untuk menjadikan alam maya sebagai landasan untuk membina identiti, namun mereka mungkin tidak sedar tentang kesan terhadap penggunaan mereka yang mempunyai impak terhadap kehidupan mereka. Rata-ratanya penggunaan internet oleh remaja memerlukan pemantauan ibu bapa kerana mereka terdedah kepada pelbagai jenis isi kandungan di alam siber. Pemantauan ibu bapa adalah antara kaedah untuk memastikan remaja menggunakan internet dengan selamat.

\section{Kesan Internet kepada Remaja}

Apabila membincangkan tentang kesan internet kepada remaja, sering kali dikaitkan penggunaan internet oleh remaja dengan perbuatan salah laku dan kesan negatif terhadap diri mereka. Hakikatnya kesan perlu dilihat dalam dua sudut pandangan iaitu kesan positif dan kesan negatif. Tidak dinafikan internet banyak memudahkan urusan harian dalam konteks keluarga khususnya dalam situasi pandemik global Covid 19. Oleh kerana sekolah terpaksa ditutup sebagai salah satu langkah bagi mengelakkan penularan wabak ini, sesi pembelajaran dijalankan secara dalam talian bagi sekolah-sekolah dan universiti (Fernandes, 2020). Sehubungan itu, keperluan untuk internet meningkat bagi tujuan pembelajaran menerusi aplikasi GoogleMeet, Zoom dan GoogleClassroom. Selain itu, penggunaan 
internet dalam kalangan remaja juga penting sebagai platform untuk hiburan pada masa lapang seperti permainan dalam talian, menonton drama dan filem serta mendengar muzik menerusi YouTube, Netflix dan Spotify. Seterusnya internet juga bertindak sebagai medium untuk berinteraksi dengan kawan-kawan dan saudara mara menerusi media sosial dan WhatsApp. Selain itu melayari internet untuk mendapatkan maklumat bagi tugasan pembelajaran dan tren terkini. Sehubungan itu, internet menjadi platform untuk remaja meneruskan kehidupan harian bagi mengikuti pembelajaran, berhibur dan berinteraksi meskipun menghadapi kekangan kerana tidak dapat berjumpa secara fizikal.

Bagaimanapun, penggunaan internet yang berlebihan serta tanpa kawalan boleh menyebabkan kesan negatif kepada remaja. Peningkatan dalam penggunaan internet turut dikaitkan dengan ketagihan Internet. Salah satu faktor penyumbang kepada ketagihan internet adalah permainan dalam talian yang memberi kesan negatif kepada remaja (Benrazavi et al., 2015). Meskipun permainan dalam talian adalah antara aktiviti yang baik untuk perkembangan minda dan kreativiti, namun penggunaan yang tidak dikawal boleh mengganggu aktiviti kehidupan harian yang lain. Akibatnya, wujud kebergantungan yang tinggi terhadap internet. Di Malaysia, aktiviti internet oleh remaja lazimnya adalah untuk rangkaian sosial, permainan dalam talian, melayari laman web, memuat turun kandungan, ruang sembang, TV internet, berita, membeli-belah, berkongsi fail dan blog. Lantas, masa yang dihabiskan untuk aktiviti dalam talian setiap hari adalah antara satu hingga lima jam sehari (Murugesan et al., 2018). Ini selari dengan kajian yang dilakukan di barat bahawa media sosial dan permainan dalam talian adalah aktiviti penting bagi remaja (Konnig, 2018). Kegiatan ini boleh menyebabkan tingkah laku penggunaan internet secara kompulsif seperti Penggunaan Internet Bermasalah (PIU) atau ketagihan Internet dan ketergantungan tinggi pada internet.

Salah satu faktor penyumbang kepada ketagihan internet adalah penggunaan peranti digital bersifat pintar seperti telefon pintar dan tablet komputer. Ketagihan dan kebergantungan kepada internet menyebabkan remaja tidak boleh berjauhan dengan peranti pintar mereka. Maka wujudlah Nomophobia iaitu No mobile phone phobia iaitu ketagihan kepada telefon pintar. Istilah yang berasal dari negara England ini merujuk kepada perasaan takut, gelisah dan tidak selesa apabila tidak menggunakan telefon mudah alih (Ahmed et al., 2019). Akibatnya remaja sentiasa memeriksa telefon dari masa ke semasa sehingga menjadi tabiat kerana tidak mahu ketinggalan dengan aktiviti rakanrakan. Misalnya, memeriksa panggilan tidak dijawab, mesej, pesanan ringkas seperti WhatsApps. Perbuatan ini secara tidak langsung menjerumuskan pengguna remaja kepada penggunaan kompulsif yang sukar untuk berhenti dan seterusnya membawa kepada ketagihan telefon pintar dan internet. Penggunaan telefon pintar yang berlebihan turut membawa kepada gangguan technostress, kesihatan mental serta kesan kepada psikologi dan biologi akibat tingkah laku kompulsif ini (Charles et al., 2013). Kesan terhadap mental dan perasaan berupaya untuk membahayakan kerana remaja berkemungkinan akan mencederakan diri sendiri atau bertindak untuk membunuh diri. Satu kes yang berlaku di Malaysia iaitu seorang remaja berusia 16 tahun didapati cuba membunuh diri dengan meniti di tepi jejambat Bukit Tinggi dalam keadaan berbahaya di Lebuh Raya Kuala Lumpur-Karak kerana ayahnya merampas telefon bimbit dan menegur kerana asyik bermain permainan video (Kosmo, 2021).

Selain itu, penggunaan internet dan peranti mudah alih juga menyebabkan remaja menjadi terlalu sibuk bersendirian berbanding dengan meluangkan masa dengan ahli keluarga. Terdapat pandangan yang mengaitkan penggunaan teknologi seperti internet dan komputer memberi pengaruh negatif kepada keluarga (Haniff, 2013). Teknologi berupaya memberi kesan sama ada untuk mengukuhkan atau menjejaskan hubungan sesebuah keluarga (Romero-Ruiz, 2017). Dalam masa yang sama kegiatan remaja di internet turut menambah cabaran kepada ibu bapa pada hari ini. Lebih merumitkan keadaan adalah penggunaan peranti mudah alih dan internet tanpa wayar telah mewujudkan budaya bilik tidur (bedroom culture) dalam kalangan remaja. Untuk golongan remaja, budaya bilik tidur menterjemahkan ruang yang berkait rapat dengan identiti, privasi dan diri mereka. (Livingstone, 2007). Ruang ini merujuk kepada bilik tidur dan tempat untuk remaja meluangkan masa bersendirian tanpa kehadiran ahli keluarga yang lain. Budaya ini menyebabkan remaja meluangkan masa bersendirian di dalam bilik masing-masing dan umpama menyisihkan diri daripada aktiviti keluarga. Ramai remaja sekarang menggunakan internet di bilik tidur mereka untuk menggunakan internet. Oleh itu, ibu bapa berkemungkinan tidak menyedari aktiviti internet yang dilakukan oleh anak mereka termasuk dengan siapa si anak berinteraksi dalam talian dan sebagainya. 
Sifat internet yang tidak mengenal sempadan juga mendedahkan pengguna remaja kepada pelbagai kesan negatif dan risiko. Sebagai contoh, isu buli siber yang meninggalkan kesan kepada emosi remaja. Sementara itu penggunaan peranti teknologi juga mempengaruhi perkembangan sosial dan kesihatan kepada pengguna muda. Penggunaan peranti teknologi menyebabkan masalah penglihatan, sikap kurang sabar, penguasaan bahasa yang lemah, kurang kemahiran sosial, perkembangan fizikal, interaksi dan akademik (Salmah \& Malisah, 2015, Naquiah et al., 2018). Selain itu, penggunaan teknologi ini juga menyebabkan golongan muda leka dengan aktiviti-aktiviti yang disajikan di internet. Isu kesan negatif internet juga menimbulkan kebimbangan kepada ibu bapa khususnya terhadap keselamatan remaja ketika melayari internet. Antara kebimbangan ibu bapa adalah tentang maklumat peribadi remaja. Sebagai contoh berkongsi atau memberi maklumat peribadi kepada individu atau pihak yang tidak dikenali. Diikuti dengan perbuatan memuat turun virus tanpa disedari ketika melayari pautan serta isu buli siber (Ofcom 2016). Selain itu remaja juga mungkin tidak tahu bahawa laman web yang dilayari membawa pautan kepada laman pornografi. Sehubungan itu, mediasi ibu bapa terhadap penggunaan internet oleh remaja adalah penting dalam memantau dan membimbing remaja pada era digital.

\section{Mediasi Ibu bapa terhadap penggunaan Internet remaja}

Mediasi ibu bapa adalah strategi yang digunakan oleh ibu bapa dalam memantau anak-anak menggunakan media. Tujuan strategi ini adalah untuk mengurangkan kesan negatif terhadap anakanak apabila menggunakan media. Pada asalnya pelaksanaan mediasi ibu bapa adalah terhadap aktiviti menonton televisyen oleh kanak-kanak. Bagaimanapun strategi ini mengalami perkembangan dengan munculnya penggunaan teknologi internet, media sosial serta komputer. Mediasi ibu bapa dalam konteks teknologi digital adalah bertujuan untuk anak-anak menggunakan media baharu seperti nternet sebagai platform peluang untuk kembangkan kemahiran dan pengetahuan secara positif (Clark, 2011). Meskipun mediasi ini pada asalnya memfokuskan kepada audien kanak-kanak, namun dengan perkembangan teknologi digital, maka boleh diguna pakai dalam konteks mediasi ibu bapa terhadap remaja. Tambahan pula, deklarasi oleh Unicef turut menetapkan bahawa ibu bapa bertanggungjawab dalam memastikan kanak-kanak dan remaja menggunakan internet dengan selamat.

Strategi mediasi ibu bapa adalah untuk memantau kegiatan anak-anak di internet dengan tujuan memaksimumkan penggunaan internet untuk perkara yang bermanfaat dan seterusnya meminimumkan risiko terhadap kanak-kanak dan remaja (Livingstone et al., 2017). Strategi ini adalah pendekatan secara interpersonal di antara ibu bapa dan anak-anak dalam konteks komunikasi keluarga dalam era digital. Pada era ini, teknologi telah memanfaatkan pelbagai peringkat golongan dan kelompok masyarakat. Ini termasuklah dalam konteks kekeluargaan iaitu hubungan ibu bapa dan anak-anak yang mana teknologi memberi nilai tambah dalam memudahkan urusan komunikasi.

Terdapat tiga jenis mediasi utama iaitu mediasi aktif, mediasi sekatan dan mediasi penggunaan bersama. Kesemua mediasi ini merujuk kepada penglibatan ibu bapa terhadap penggunaan media oleh anak-anak menerusi pendekatan komunikasi (Clark, 2011). Sehubungan itu, mediasi ibu bapa diperluaskan kepada pengaruh ibu bapa terhadap pengalaman dan penggunaan internet iaitu pembabitan ibu bapa menerusi strategi untuk mengawal penggunaan media teknologi oleh anak-anak sebagai pendidikan media (Zaman et al., 2016). Dalam konteks penggunaan internet dan media digital, strategi ini lazimnya digunakan untuk meneroka kesan peluang dan risiko dalam talian ke atas kanakkanak dan remaja. (Rodriguez-de-Dios, 2018, Livingstone et al., 2017). Berdasarkan kepada kajiankajian ini, praktis mediasi yang berbeza memberi kesan yang berlainan.

Mediasi aktif merujuk kepada ibu bapa yang berbual, berbincang dan berkongsi pengalaman dengan anak-anak tentang isi kandungan media. Sebagai contoh berbincang tentang aktiviti dalam talian, laman sesawang yang bermanfaat, isu bahaya yang mengancam dalam talian dan langkah berjaga-jaga ketika menggunakan internet (Shaji \& Sebastian, 2020). Cara ini adalah dengan tujuan untuk anakanak memahami tentang isi kandungan internet dan menggunakan internet dengan selamat. Ibu bapa yang cenderung untuk bimbang tentang risiko kesan internet terhadap anak-anak menggunakan kaedah 
ini. Seterusnya, mediasi sekatan adalah kaedah ibu bapa menetapkan peraturan dan garis panduan untuk mengawal dan mengehadkan masa penggunaan media oleh anak-anak. Antara klasifikasi kawalan dalam strategi ini adalah terhadap tempoh masa penggunaan, jenis kandungan media dan sekatan umur untuk menggunakan internet (Grizollo \& Scorsolini-Comin, 2020). Keadaan ini adalah kerana ibu bapa prihatin terhadap kesan buruk penggunaan teknologi terhadap anak-anak. Bagaimanapun, mediasi sekatan telah mengurangkan kemahiran digital remaja akibat kurang pendedahan seterusnya menjurus kepada kurangnya berlaku risiko.

Strategi penggunaan bersama pula merujuk kepada strategi ibu bapa untuk menggunakan internet dan berkongsi aktiviti internet bersama anak-anak. Salah satu caranya adalah ibu bapa berada bersama dengan anak-anak ketika menggunakan internet. Antaranya adalah menonton video seperti drama atau filem dalam talian, media sosial atau melayari laman sesawang untuk mencari sesuatu maklumat berdasarkan minat yang sama. Ibu bapa juga memantau aktiviti internet anak-anak secara berterusan (Shaji dan Sebastian 2020). Kaedah ini secara tidak langsung membantu ibu bapa untuk mengawasi penggunaan internet oleh anak-anak. Berteraskan kepada tiga jenis mediasi ibu bapa ini, dimensi ini dikembangkan lagi dan beberapa sarjana memperkenalkan variasi kepada strategi ini. Klasifikasi empat dimensi yang merangkumi penggunaan bersama aktif, sekatan berinteraksi, sekatan teknikal dan pemantauan (Livingstone dan Helsper 2008). Sementara itu, mediasi keselamatan aktif, mediasi sekatan kandungan, mediasi sekatan teknikal dan pemantauan (Nathalie et al., 2013).

Memandangkan mediasi ibu bapa bertujuan untuk memaksimumkan peluang penggunaan internet secara positif dan meminimumkan risiko kepada kanak-kanak dan remaja, terdapat pelbagai fokus kajian telah dijalankan dengan berpandukan kepada konstruk ini. Kajian dalam strategi mediasi ibu bapa terhadap penggunaan media sosial dan literasi media sosial dalam kalangan anak-anak mendapati ibu bapa yang memiliki literasi media sosial memilih pendekatan mediasi aktif ke atas anak-anak remaja. Menerusi mediasi aktif, ibu bapa dapat berbincang dengan anak-anak tentang aktiviti di media sosial disebabkan mereka memahami tentang penggunaan media sosial (Daneels \& Vanwynsberghe, 2017). Sementara itu kajian lain pula fokus kepada strategi mediasi ibu bapa terhadap risiko dalam talian berhubung dengan penggunaan internet oleh anak-anak mendapati pendekatan mediasi ibu bapa adalah bergantung kepada keadaan sesebuah keluarga yang meliputi faktor masa, tingkah laku dan karakter anak-anak (Smahelova et al., 2017). Secara ringkasnya, setiap dimensi mediasi yang digunakan adalah bertujuan untuk menyokong remaja menggunakan internet secara berhemah dan selamat.

\section{Perbincangan}

Menyedari akan kesan internet dan teknologi terhadap remaja, ibu bapa perlu ambil perhatian dan memainkan peranan penting dalam mendidik anak-anak tentang penggunaan internet secara berhemah dan selamat. Keperluan ini adalah bertujuan untuk memastikan kesejahteraan keluarga dapat dikekalkan seiring dengan persekitaran digital pada hari ini. Selain itu, aspek keselamatan anak-anak ketika dalam talian dan hubungan sesama manusia juga harus dikekalkan. Pokoknya adalah bagaimana manusia selaku pengguna berperanan untuk menginsafkan teknologi. Bukannya menghasilkan manusia sebagai jentera berautomasi. Dengan demikian, institusi keluarga khususnya ibu bapa memainkan peranan penting dalam memastikan pembentukan masyarakat yang cekap menggunakan teknologi berjalan seiring dengan nilai kemanusiaan. Proses pembentukan ini hendaklah bermula pada peringkat kanak-kanak dan remaja.

Kajian terhadap peranan teknologi digital dalam rutin harian kanak-kanak di bandar mendapati kanakkanak khususnya remaja memerlukan mediasi ibu bapa sebagai pengawasan bagi memastikan penggunaan teknologi secara selamat (Galera et al., 2016). Dalam konteks persepsi ibu bapa terhadap peranan media baharu khususnya penggunaan peranti sentuh skrin dalam keluarga, kajian memperoleh peranti bersifat sentuhan membawa pengaruh negatif terhadap psikologi, fizikal dan perkembangan kognitif anak-anak. Untuk itu, peranan ibu bapa adalah mengawal penggunaan media oleh anak-anak (Seo \& Lee, 2017). Kajian lain turut mengambil kira penggunaan peralatan teknologi digital di rumah yang mana dapatan menunjukkan ibu bapa perlu mengawasi aktiviti internet anak-anak meskipun 
mereka berada di hadapan mata ibu bapa (Ponte 2016). Berdasarkan kajian-kajian lepas mendapati tentang pentingnya mediasi ibu bapa dalam mengawal penggunaan teknologi digital oleh anak-anak di era ini. Mediasi ibu bapa dalam kajian-kajian ini melihat kepada strategi ibu bapa menerusi tiga elemen iaitu mediasi sekatan, mediasi aktif dan mediasi penggunaan bersama.

Berdasarkan kepada kajian lepas juga, mediasi ibu bapa berupaya untuk membendung ketagihan internet yang menyebabkan depresi akibat buli siber dalam kalangan remaja (Chang et al., 2015). Penggunaan internet yang berlebihan dapat dikawal apabila ibu bapa mempraktikkan strategi mediasi terhadap anak-anak remaja (Kalmus et al., 2015). Mediasi ibu bapa turut dikaji ke atas permainan video dan dalam talian. Ibu bapa yang beranggapan permainan video membawa kesan negatif terhadap tingkah laku anak-anak mengamalkan mediasi yang lebih tegas atau sekatan (Kousari dan Mehrabi 2017). Dengan cara sekatan secara tidak langsung dapat mengurangkan tempoh pendedahan remaja dalam talian. Selaras dengan pandangan itu, ibu bapa yang memantau permainan dalam talian berupaya untuk meminimumkan kesan negatif terhadap anak-anak (Benrazavi et al., 2015).

Di Malaysia, strategi mediasi ibu bapa berfungsi bagi memastikan kanak-kanak menggunakan internet secara positif. Apabila kanak-kanak tahu akan tujuan menggunakan internet maka ia membawa kebaikan dengan aktiviti yang bermanfaat. (Azlina et al., 2014). Sementara itu, projek European Kids Online memperkenalkan Parental Mediation Model (PMM) yang terdiri daripada lima-faktor iaitu mediasi teknikal, pemantauan, sekatan, aktif keselamatan internet dan mediasi aktif penggunaan internet. Bagaimanapun, disebabkan gaya keibubapaan dan didikan anak-anak di negara ini tidak sama dengan gaya yang diamalkan di luar negara, maka PMM versi Malaysia perlu diperkenalkan dan strategi mediasi ibu bapa hendaklah bersesuaian dengan konteks masyarakat Malaysia (Misha et al., 2014).

Secara keseluruhan berdasarkan kajian lepas, mediasi aktif adalah kaedah yang berkesan dan terbaik untuk mengelakkan tingkah laku yang tidak baik di dalam talian. Seterusnya mengekalkan saluran komunikasi yang baik di antara ibu bapa dan anak-anak dengan berlandaskan kepada kepercayaan dan bimbingan kepada anak-anak khususnya remaja. Manakala mediasi sekatan adalah lebih berkesan terhadap kanak-kanak yang lebih muda berbanding dengan remaja (Grizolio \& Scorsolini-Comin, 2020). Bagaimanapun, mediasi sekatan didapati paling berkesan dalam mengurangkan risiko dan kesan negatif seperti menonton isi kandungan yang tidak sesuai yang berunsurkan seksual dan keganasan, buli siber, pendedahan maklumat peribadi serta pencerobohan privasi pengguna muda (Shaji \& Sebastian, 2020).

Sementara itu kebanyakan kajian tentang pembabitan, peranan dan mediasi ibu bapa terhadap penggunaan media baharu oleh kanak-kanak mendapat perhatian di luar negara. Meskipun sudah ada kajian mediasi ibu bapa di Malaysia, namun kajian ini memerlukan kesinambungan mengikut peredaran masa. Kajian tentang peranan, pemantauan dan mediasi ibu bapa di Malaysia perlu diperluaskan. Terdapat jurang yang masih belum diterokai dalam penyelidikan bidang mediasi ibu bapa samada di Malaysia mahupun luar negara. Dengan demikian, praktis mediasi ibu bapa adalah salah satu cara yang boleh digunakan untuk memantau penggunaan internet oleh remaja bagi memaksimumkan manfaat dan meminimumkan risiko terhadap keselamatan remaja ketika di dalam talian.

\section{Kesimpulan}

Membesarkan anak-anak pada era digital ini memerlukan usaha ibu bapa untuk maju ke hadapan bersama anak-anak dalam menggunakan teknologi khususnya internet dan peranti digital seperti telefon pintar, komputer dan tablet komputer. Penggunaan teknologi ini adalah satu keperluan pada masa kini kerana semakin banyak urusan perlu dilaksanakan menerusi internet dan penggunaan peranti pintar. Keengganan menggunakan teknologi ini menyebabkan ibu bapa dan anak-anak ketinggalan ke belakang. Oleh itu, ibu bapa perlu menggalak dan membenarkan anak-anak untuk menggunakan internet dan peranti pintar tetapi dalam masa yang sama mempunyai strategi pemantauan bagi memastikan anak-anak menggunakan internet untuk aktiviti yang bermanfaat dan menghindari perkaraperkara yang memudaratkan dan membahayakan fizikal dan mental mereka. Ibu bapa pada era digital 
ini hendaklah memahami pola penggunaan internet anak-anak mereka yang kebanyakannya untuk tujuan pembelajaran, pengetahuan, komunikasi dan hiburan. Seterusnya menyedari tentang kesan internet dari segi kebaikan dan keburukan terhadap anak-anak. Peningkatan terhadap penggunaan internet dalam kalangan kanak-kanak dan remaja dikaitkan dengan keperluan untuk mediasi ibu bapa. Mediasi ibu bapa adalah antara strategi untuk ibu bapa memantau penggunaan internet anak-anak.

\section{Rujukan}

Abdul Rashid Abdul Rahman (2021, Mac 16) Cuba bunuh diri selepas ditegur main permainan video. https://www.kosmo.com.my/2021/03/16/

Ahmed, S., Pokhrel, N., Roy, S. \& Samuel, A.J. (2019). Impact of nomophobia: A nondrug addiction among students of physiotherapy course using an online cross-sectional survey. Indian $J$. Psychiatry 2019, 61, 77-80

Ali Salman. \& Mohd Safar Hasim, (2011) Internet Usage in a Malaysian Sub-Urban Community: A Study of Diffusion of ICT Innovation. The Innovation Journal: The Public Sector Innovation Journal, Volume 16(2), 2011, article 6.

Ali Salman., Er Ah Choy, Wan Amizah Wan Mahmud, \& Roslina Abdul Latif. (2013) Tracing the Diffusion of Internet in Malaysia: Then and Now. Asian Social Science; Vol. 9, No. 6; 2013. ISSN 1911-2017 E-ISSN 1911-2025. Published by Canadian Center of Science and Education

Anderson, M. \& Jiang, J. (2018) Teens, Social Media \& Technology 2018. Pew Research Center, May 2018, “Teens, Social Media \& Technology 2018

Azlina Daud, Siti Zobidah Omar, Md Salleh Hassan, Jusang Bolong \& Misha Teimouri. (2014). Parental mediation of children's positive use of the Internet. Life Science Journal 2014: 11 (8) : 360-369.

Benrazavi, R., Teimouri, M., \& Griffiths, M.D. (2015). Utility of parental mediation model on youth's problematic online gaming. International Journal Mental Health and Addiction.13(6), pp. 712727.

Chang, F.C., Chiub, C.H.,Miaoc, N.F., Chen, P.H., Lee, C.M., Chiang, J.T., Pan, Y.C. (2015). The relationship between parental mediation and Internet addiction among adolescents, and the association with cyberbullying and depression. Comprehensive Psychiatry.57 (2015) 21-28.

Charles, S.T, Piazza, J.R., Mogie, J., Silwinski, M.J., \& Alemida D.M. (2013). The wear and tear of daily stressors on mental health. Psychological Science. 24(5) 733-741

Chassiakos, Y.R., Radesky, J., Christakis, D., \& Moreno, M.A. (2016). Children and adolescents and digital media. AAP Council on Communications and Media. Pediatrics. 2016;138(5): e20162593

Clark, L. (2011). Parental mediation theory for the digital age. Communication theory. 21, 323-343.

Daneels, R., \& Vanwynsberghe, H. (2017). Mediating social media use: connecting parents' mediation strategies and social media literacy. Cyberpsychology: Journal of Psychosocial Research on Cyberspace. 11(3), article 5.

Digi.com.my. 2021. Digi celebrates decade-long commitment for a safer internet.

Elhai, J.D., Dvorak, R.D., Levine J.C. \& Hall, B.J. (2017). Problematic smartphone use : a conceptual overview and systematic review of relations with anxiety and depression psychopathology. Journal of Affective Disorders. 207 (2017) 251-259

Fernandes, B., Biswas, U.N., Tan-Mansukhani, R., Vallejo, A. \& Essau, C.A. (2020) The impact of COVID-19 lockdown on internet use and escapism in adolescents. Revista de Psicología Clínica con Niños y Adolescentes. Vol. 7 n ${ }^{\circ} .3$ - Septiembre 2020 - pp 59-65.

Galera, N., Matsumoto, M. \& Poveda, D. (2016). The place of digital devices in the home and family routines of young children (3-7) in Madrid. Media Education. Vol. 7, n. 2, pp. 303-319

Grizólio, T.C \& Scorsolini-Comin. F. (2020). How Has Parental Mediation Guided Internet Use By Children and Adolescents? Psicologia Escolar e Educacional. 2020, v. 24

Haniff Hassan, Jusang Bolong, Siti Zobidah Omar, Narimah Ismail \& Musa Abu Hassan (2013) Implikasi penggunaan komputer terhadap pola komunikasi keluarga dan masa berkomunikasi dalam keluarga petani Melayu di Malaysia. Jurnal Elektronik Jabatan Bahasa \& Kebudayaan Melayu . Jilid 4.

Ismail Sualman (2019, November 3) Ketagihan media sosial sudah serius. https://www.sinarharian.com.my/article/55317/KOLUMNIS 
Iqbal, S., Zakar, R. \& Fischer, F. (2021) Predictors of parental mediation in teenagers' internet use: a cross-sectional study of female caregivers in Lahore, Pakistan. BMC Public Health (2021) 21:317

Kalmus,V., Blinka, L., \& Olafsson, K. (2015). Does it matter what mama says: evaluating the role of parental mediation in European adolescents' excessive Internet use. Children \& Society. Volume 29 , pp. $122-133$

Koning, I. M., Peeters, M., Finkenauer, C. \& Van Den Eijnden, R. (2018). Bidirectional effects of Internet-specific parenting practices and compulsive social media and Internet game use. Journal of Behavioral Addictions 7(3), pp. 624-632 (2018). DOI: 10.1556/2006.7.2018.68

Kousari, M., \& Mehrabi, M. (2017). Parental mediation of children's video game experiences: Iranian parents' strategies of mediation. International Journal of Social Sciences (IJSS) Vol.7, No.1, 2017

Lakshmana G, Kasi S, Rehmatulla M. (2017). Internet use among adolescents: Risk-taking behavior, parental supervision, and implications for safety. Indian J Soc Psychiatry 2017;33:297-304

Livingstone, S. (2007) From family television to bedroom culture: Young people's media at home. In E. Devereux (Ed.), Media Studies: Key issues and Debates (302-321). London: Sage.

Livingstone, S., \& Helsper, E. J. (2008). Parental mediation of children's Internet use. Journal of Broadcasting \& Electronic Media, 2008, 52(4), 581-599.

Livingstone, S., Ólafsson, K., Helsper, E.,J., Lupiáñez-Villanueva, F., Veltri, G.A. \& Folkvord, F. (2017). Maximizing opportunities and minimizing risks for children online: the role of digital skills in emerging strategies of parental mediation. Journal of Communication .

Lupton, D., Pedersen, S. \& Thomas, G.M. (2016) Parenting and Digital Media: From the Early Web to Contemporary Digital Society. Sociology Compass 10/8 (2016), 730-743.

Misha Teimori, Md Salleh Hassan, Jusang Bolong, Ezhar Tamam, Nor Azura Adzaruddin \& Azlina Daud. (2014). Re-examining Parental Mediatiion Model For Children Internet Safety. Journal of Language and Communication. 1(2), 209-220

Nadia Hamid (2017, Oktober 22). Remaja, Kanak-kanak Ketagihan Internet Serius. https://www.bharian.com.my/berita/nasional/2017/

Naquiah Nahar, Sahrunizam Sangi, Dharsigah A/P Baniear Salvam, Nurhidayu Rosli \& Abdul Hafiz Abdullah. (2018). Impak Negatif Teknologi Moden Dalam Kehidupan Dan Perkembangan Kanak-Kanak Hingga Usia Remaja. International Journal of Islamic and Civilizational Studies. 01 (2018) pp. 87-99|

Nathalie.S, Nikken.P \& Haan. J. D. (2013). Determinants of Internet Mediation. Journal of Children and Media, 2013 7(1), $96-113$.

Noorma Razali, Siti Farhannie Mohd Adnan, Siti Marziah Zakaria \& Khaidzir Hj Ismail (2018) Kepentingan Pemantauan Media Ibu Bapa Ke Arah Kesejahteraan Positif Kanak-Kanak Awal. Simposium Kebangsaan Kanak-Kanak dan Keluarga. Universiti Malaysia Sabah.

Normah Mustafa, Wan Amizah Wan Mahmud, Fauziah Ahmad, Maizatul Haizan Mahbob \& Mohd Helmi Abd Rahim. (2013). Kebergantungan Internet dan aktiviti online remaja di Lembah Kelang. Journal Komunikasi.

Nurhamizah Hashim \& Asbah Razali (2019) Teknologi dan Media Sosial dalam Komunikasi Ibubapa dan Anak-anak. Jurnal Komunikasi: Malaysian Journal of Communication. Jilid 35(4) 2019: 337352

Pillai, S. (2001). Malaysia's oldest search engine upbeat in trying times. CNETAsia.

Ofcom. (2016). Children and parents. Media Use and Attitudes Report 2016.

Ponte, C. (2016). Contextualising digital practices at home - Whose contexts? Whose homes?. Centro de Investigação em Educação (CIEd)

Raja Kumar Murugesan, Siti Khadijah Binti Mohd Hamzaht \& Supriyanto. (2018) A Study on internet addiction among teenagers in Selangor state of Malaysia. MATEC Web of Conferences 218, 03018

Rahmah Ghazali (2017, September 20). Celcom introduces KidSafe app to track children's online activities. https://www.thestar.com.my/news/nation/2017/09/20

Rodríguez-de-Dios, I., van Oosten, J.M.F, Igartua, J.J. (2018). A study of the relationship between parental mediation and adolescents' digital skills, online risks and online opportunities. Computers in Human Behavior. 82 (2018) 186-198

Romero-Ruiz, K., Echeverri-Sáncheza, L., Peña-Plataa, J., Vásquez-Giraldod, S., Aguilera-Cardonaa, M., Herazo-Avendañoa, C., Valencia- Arias, A., \& Bran-Piedrahita, L. (2017). Information and 
communication technologies impact on family relationship. Procedia - Social and Behavioral Sciences 237 ( 2017 ) $30-37$

Salmah Omar dan Malisah Latip. (2016). Pengaruh peranti teknologi kepada perkembangan sosial dan permasalahan kesihatan kanak-kanak.

Seo, H. \& Lee, C.S. (2017). Emotion matters: What happens between young children and parents in a touchscreen world. International Journal of Communication. 11(2017), 561-580

Shaji, M. \& Sebastian, T. (2020). Parental Mediation of Adolescents' Internet Use. International Journal of Behavioral Sciences. 10.30491/ijbs.2020.214319.1185

Smahelova, M., Juhová, D., Cermak, I., Smahel, D. (2017). Mediation of young children's digital technology use: the parents' perspective. Cyberpsychology: Journal of Psychosocial Research on Cyberspace. 11(3), article 4.

Unicef. (2017). The State of the World's Children 2017: Children in a Digital World. United Nations Children's Fund (UNICEF). December 2017

Utusan Malaysia. 2016. Peranan Ibu bapa Kawal Anak-anak Guna Internet. 25 September 2016

Utusan Malaysia. 2018. Panduan Keibubapaan Zaman Digital. 12 Februari 2018

Wisniewski, P.J, Xu, H., Rosson, M.B.,\& Carroll, J.M. (2014). Adolescent online safety: the moral of the story. In Proceedings of the 17th ACM conference on Computer supported cooperative work \& social computing. ACM, 1258-1271.

Zaman, B., Nouwen, M., Vanattenhoven, J., Ferrerre, E. \& Van Looy, J. (2016). A qualitative inquiry into the contextualized parental mediation practices of young children's digital media use at home, Journal of Broadcasting \& Electronic Media. 60:1, 1-22. 